\title{
Mirror mirror on the ward, who's the most narcissistic of them all? Pathologic personality traits in health care
}

\author{
Vittoria Bucknall MBChB, Suendoss Burwaiss BSc, Deborah MacDonald BA, Kathy Charles PhD, \\ Rhys Clement BMBS
}

\begin{abstract}
Background: Stereotypes in medicine have become exaggerated for the purpose of workplace amusement. Our objective was to assess the levels of "dark triad" personality traits expressed by individuals working in different health care specialties in comparison with the general population.
\end{abstract}

Methods: We conducted a prospective, crosssectional study within multiple departments of a UK secondary care teaching hospital. A total of 248 health care professionals participated, and 159 members of the general population were recruited as a comparison group. We measured 3 personality traits narcissism, Machiavellianism and psychopathy - through the validated self-reported personality questionnaires Narcissistic Personality Inventory (NPI), MACH-IV and the Leven- son Self-Report Psychopathy Scale (LSRP), respectively.

Results: Health care professionals scored significantly lower on narcissism, Machiavellianism and psychopathy (mean scores 12.0, 53.0 and 44.7, respectively) than the general population ( $p<$ 0.001). Nursing professionals exhibited a significantly higher level of secondary psychopathy than medical professionals ( $p=0.04$, mean LSRP score 20.3). Within the cohort of medical professionals, surgeons expressed significantly higher levels of narcissism ( $p=0.03$, mean NPI score 15.0).

Interpretation: Health care professionals expressed low levels of dark triad personality traits. The suggestion that health care professionals are avaricious and untrustworthy may be refuted, even for surgeons.
I was quietly admiring my astonishing good looks in the mirror of the operating theatre changing room when one of my anesthesiologist colleagues brazenly interrupted me: "Typical surgeon - you love yourselves so much we'll need to have the mirrors removed in here if we are to get any work done!" I was somewhat bemused by the 2 obvious inaccuracies in this comment: first, that all surgeons love themselves and, second, that theatre workflow is ever dependent on the work ethos of the surgical team! I immediately went on the counteroffensive by replying, "Don't worry, sudoku writers are on strike this week so we should be finished before lunch!"

These lighthearted, tongue-in-cheek exchanges between medical professionals occur around the world every day and are based on popular stereotypes that have become exaggerated for the purpose of workplace amusement. One might imagine neanderthalic orthopedic surgeons instinctively reaching for a bigger hammer as the singular solution to any problem, grumpy radiologists growling at anyone who dares disturb their dark sanctuary and dour internists glacially grinding their way through a ward round, which necessitates a packed lunch, comfortable walking shoes and a hospital map.

Many stereotypes have filtered into the public domain, where emphasis on negative traits can be misleading for the general public. The callous notion that doctors are self-centred, avaricious and untrustworthy is currently being bandied around the media. ${ }^{1,2}$ There is a real danger of these negative stereotypes eroding the high level of regard in which the profession is held. Perhaps the most undesirable personality characteristics are those that form the "dark triad": a trio of Machiavellianism, narcissism and psychopathy. ${ }^{3}$

Those expressing Machiavellian traits are deceptive, self-interested and succeed through the exploitation of others. ${ }^{4-6}$ Narcissism is defined as a "normal" personality trait at low levels and is characterized by the expression of pride,
Competing interests: None declared.

This article has been peer reviewed.

Accepted: Oct. 20, 2015

Print: Dec. 8, 2015

Correspondence to:

Vittoria Bucknall, vittoria. bucknall@doctors.org.uk

CMAJ 2015. DOI:10.1503 /cmaj.151135 
egotism and vanity. ${ }^{7,8}$ Psychopathy manifests as antisocial behaviour expressing callousness, remorselessness and selfishness, with little empathy and a high level of impulsivity. ${ }^{9,10}$ It has been proposed that 2 variants of psychopathy exist: primary and secondary. Primary psychopathy is believed to be a genetic predisposition to certain behavioural patterns, which include cool, calm, meticulous forward planning and emotional dissociation. Secondary psychopathy, however, is an adaptation to environmental factors and involves impulsivity and emotional instability, which can place others at risk. ${ }^{11}$

It is hypothesized that some of these dark personality traits are present within the health care profession and, more specifically, within certain disciplines. It is not implausible for one to conceive that the self-assured surgeon could display evidence of vanity or that the irrational nurse might exhibit psychopathic tendencies. However, scientific evidence is lacking to support or quantify the existence of such personality traits in the health care profession.

The aim of this study was to assess levels of dark triad personality traits among individuals working in health care in comparison with the general population.

\section{Methods}

This prospective, cross-sectional study was conducted over a 1-year period (August 2013 to August 2014).

We distributed 280 questionnaire packs to health care professionals in a UK secondary care teaching hospital, a university-affiliated hospital that provides tertiary care. These paper-format questionnaires were placed in communal areas of clinical work and relaxation (although areas of relaxation were often unoccupied!).

Health care workers were invited by poster advertisement to voluntarily complete the questionnaires and return them using prepaid envelopes. Eligibility criteria included any health care professional in direct contact with patient care, diagnosis or treatment. The health care group was further divided into subgroups: surgeons, hospital physicians, general practitioners, acute medical physicians, nurses and those with limited patient contact (e.g., radiologists and microbiologists).

Using snowball sampling, we recruited a comparison group comprising members of the UK general population to provide normal distributions. A Web link to the 3 questionnaires was shared through online advertising on social media sites. Participants from the general population were self-selected. Before being able to access the questionnaires, participants were required to tick a box confirming their consent to participate. This then allowed access to complete the electronic versions of the dark triad questionnaire. Once completed, the questionnaire results were electronically returned to a central Web address registered to the study research team, where data were accessed for analysis.

We measured the dark triad personality traits using well-validated questionnaire instruments. Narcissism was calculated using the Narcissistic Personality Inventory ${ }^{7}$ (NPI), which comprises 40 paired statements, one narcissistic and one nonnarcissistic, whereby the participant marked true or false with reference to themselves (Appendix 1, available at www.cmaj.ca/lookup/suppl/doi:10 .1503/cmaj.151135/-/DC1). Machiavellianism was measured using the MACH-IV, ${ }^{12}$ a 20 -statement questionnaire scored using a 5-point Likert scale (1 $=$ strongly disagree; $5=$ strongly agree) (Appendix 2, available at www.cmaj.ca/lookup/suppl/ doi:10.1503/cmaj.151135/-/DC1). Similarly, psychopathy was determined using the 26-statement Levenson Self-Report Psychopathy Scale ${ }^{13}$ (LSRP) (Appendix 3, available at www.cmaj.ca/ lookup/suppl/doi:10.1503/cmaj.151135/-/DC1).

We undertook an a priori power analysis with the methods described by Faul and colleagues ${ }^{14}$ using $G^{*}$ Power (version 3.1.9.2). We determined a required total sample size of 204 participants to achieve $85 \%$ power, a significance level of $<0.05$ and a medium effect size ( 0.25 based on Cohen $\left.{ }^{15}\right)$. In psychologic research, the a priori power analysis convention is used to compute the necessary sample size as a function of user-specified values for the required significance level, the desired statistical power and the to-be-detected population effect size.

Data were transferred onto an Excel spreadsheet (version 14.5.5). Statistical analysis was performed using the statistical package for the social sciences (SPSS, version 21). For each cohort, we calculated a parametric data analysis of the 3 personality questionnaires and included the mean and 95\% confidence intervals (CIs) for the presence of narcissism, Machiavellianism and psychopathy. We used analysis of variance (ANOVA), with Bonferroni post hoc adjustment to account for multiple comparisons, to determine whether significant differences in scores from the 3 components of the dark triad existed between the cohorts and subgroups. Significance levels were set to $p<0.05$.

Participation in the study was voluntary, and all responses were made anonymous.

\section{Results}

A total of 248 health care professionals from 23 departments (199 medical and 49 nursing professionals) took part in the study, giving a 
response rate of $88.6 \%$. In the health care cohort, 122 were female and 126 were male, and the mean age of participants was 40 (range 20-67) years. From the general population, 159 people participated; 113 were female and 46 were male, and the mean age was 26.6 (range 17-60) years.

The health care group had lower mean scores for dark triad traits than the general population (Table 1). Using ANOVA, we found significant differences for narcissism, Machiavellianism and primary psychopathy ( $p=0.003, p=0.007$ and $p=0.008$, respectively) but not for secondary psychopathy $(p=0.06)$.

Among subgroups within the health care profession, surgeons displayed a significantly higher level of narcissism ( $p=0.03$, mean NPI score 15.0) and primary psychopathy ( $p=0.04$, mean LSRP score 27.8) (Table 2). Nursing professionals exhibited a significantly higher level of secondary psychopathy than medical professionals ( $p=0.04$, mean LSRP score 20.3). Although the general practice subgroup showed the lowest levels of all 3 dark triad traits, the difference was not significant compared with the other health care subgroups.

Because the numbers of responses from each medical and surgical specialty were small, meaningful interspecialty statistical analysis was not possible. However, for interest into how dark your chosen career is, a league table of personality traits for a selection of specialties is shown in Table 3 . Of the surgical specialties that were represented in the study, vascular surgery showed the highest mean score for narcissism, with a mean NPI score of 18.5, and remained in the top 3 for Machiavellianism and psychopathy.

\section{Interpretation}

Health care professionals expressed low levels of dark triad personality traits compared with the general population. Our results show that the integrity of the health care profession remains steadfast. The low levels of Machiavellianism within this cohort prove that we are able to put our patients' concerns above our own. We are as faithful to the Hippocratic Oath today as the first time it was taken. Reassuringly, psychopaths have been steered away from the doors of medical and nursing schools into presumably more suitable careers, such as politics. As a group, health care workers are less narcissistic than the general public, with a mean score in the general population cohort similar to those reported by Raskin and Terry. ${ }^{8}$

Our data indicate that the health care community could be considered as a distinct population with its own norms for each trait. We feel that the most likely explanation for the relatively increased expression of a particular characteristic among medical professionals is due to reverse causality in self-selection to specialty. Surgeons, in particular, stand out because of their significantly elevated levels of narcissism and primary psychopathy. Working in a specialty where lives can be saved or rapidly changed for the better demands a degree of self-assurance that allows chal-

Table 1: Results for dark triad traits in 159 participants from the general population and 248 health care professionals

\begin{tabular}{|c|c|c|}
\hline \multirow[b]{2}{*}{ Trait } & \multicolumn{2}{|c|}{ Group; mean score ( $95 \%$ confidence interval) } \\
\hline & General population & Health care \\
\hline Narcissism* & $15.9(14.8-16.0)$ & $12.0(11.3-12.7)$ \\
\hline Machiavellianism $\dagger$ & $56.6(55.6-58.2)$ & $53.0(51.9-54.1)$ \\
\hline Psychopathy $\ddagger$ & $52.6(51.2-54.0)$ & $44.7(43.8-45.6)$ \\
\hline Primary & $33.4(32.6-34.2)$ & $26.4(25.7-27.1)$ \\
\hline Secondary & $19.1(18.4-19.8)$ & $18.4(18.0-18.8)$ \\
\hline \multicolumn{3}{|c|}{$\begin{array}{l}\text { *Narcissistic Personality Inventory: }{ }^{7} \text { scored } 0-40 \text {. The higher the score, the higher the level of } \\
\text { narcissism. } \\
\text { tMACH-IV: } \\
\text { fLevenson Self-Report Psychopathy Scale: }{ }^{13} \text { score, the higher the level of Machiavellianism. } \\
\text { the level of psychopathy. }\end{array}$} \\
\hline
\end{tabular}

Table 2: Results for dark triad traits in 248 health care professionals, by subgroup

\begin{tabular}{|c|c|c|c|c|c|c|}
\hline \multirow[b]{2}{*}{ Subgroup } & \multirow[b]{2}{*}{$\begin{array}{c}\text { No. of } \\
\text { participants }\end{array}$} & \multicolumn{5}{|c|}{ Trait; mean score ( $95 \%$ confidence interval) } \\
\hline & & Narcissism* & Machiavellianismt & Psychopathy $¥$ & $\begin{array}{c}\text { Primary } \\
\text { psychopathy }\end{array}$ & $\begin{array}{l}\text { Secondary } \\
\text { psychopathy }\end{array}$ \\
\hline Surgeons & 60 & $15.0(13.6-16.4)$ & $53.5(51.4-55.6)$ & $45.7(43.2-48.0)$ & $27.8(26.1-29.6)$ & $17.8(16.8-18.8)$ \\
\hline Hospital physicians & 50 & $10.8(9.3-12.3)$ & $53.6(50.8-56.4)$ & $44.3(41.5-47.1)$ & $26.0(24.1-27.9)$ & $18.2(17.0-19.4)$ \\
\hline General practitioners & 24 & $9.1(7.7-10.5)$ & $49.1(45.8-52.4)$ & $40.3(36.7-43.9)$ & $24.1(21.6-26.6)$ & $16.2(14.7-17.2)$ \\
\hline Acute medical physicians & 49 & $12.2(10.6-13.8)$ & $52.9(50.3-55.5)$ & $44.0(41.1-46.9)$ & $25.9(23.8-28.1)$ & $18.1(17.0-19.2)$ \\
\hline Limited patient contact & 16 & $10.7(7.9-13.5)$ & $53.9(51.0-56.8)$ & $43.9(40.2-47.6)$ & $25.0(22.4-27.6)$ & $18.9(17.5-20.5)$ \\
\hline Nurses & 49 & $11.1 \quad(9.6-12.7)$ & $53.5(51.1-55.9)$ & $47.3(44.8-49.8)$ & $25.7(24.0-27.4)$ & $20.3(19.1-21.6)$ \\
\hline
\end{tabular}


lenging decisions to be made with cool confidence and prompt action. This is particularly true of vascular surgery, where a ruptured abdominal aortic aneurysm is enough to rupture a hole in most people's underwear. Perhaps an "essential" quality in the person specification for recruitment to vascular surgery should be to "love thyself?"

Using this theory, we would have anticipated that our anesthesiologist colleagues would have displayed similar attributes to the surgical subgroup given the unpredictable acute nature of their work and ability to save lives in an instant. It could be proposed, however, that our data are flawed because most of the anesthesiologists who participated in this study were working in orthopedic theatres alongside surgeons who are more intellectually advanced, physically superior $^{16}$ and statistically better looking. ${ }^{17}$ It is therefore likely that this has negatively impacted their self-esteem (Figure 1). Had they been working beside their obstetrics and gynecology colleagues, their scores may have differed.

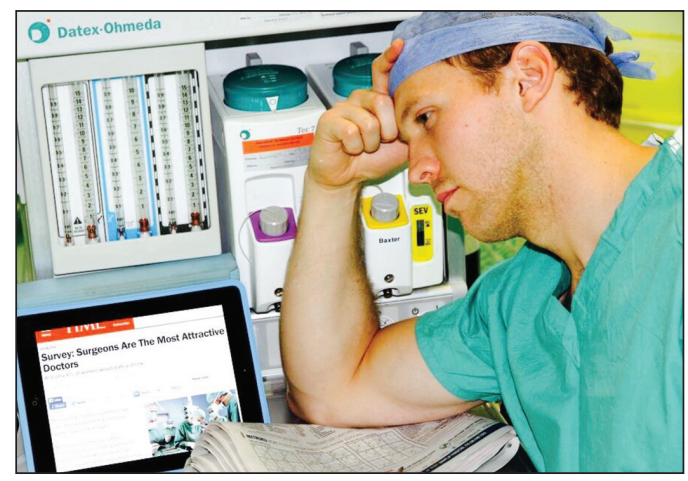

Figure 1: Anesthesiologists expressed less narcissism than expected. Is this the effect of overexposure to surgeons who are better looking, more intelligent and physically superior?

Table 3: League table of dark triad traits for health care specialties

\begin{tabular}{|c|c|c|c|c|c|c|c|c|c|}
\hline \multirow[b]{2}{*}{ Rank } & \multicolumn{3}{|c|}{ Narcissism* } & \multicolumn{3}{|c|}{ Machiavellianism† } & \multicolumn{3}{|c|}{ Psychopathy } \\
\hline & Specialty & $\begin{array}{l}\text { Mean } \\
\text { score }\end{array}$ & Subgroup & Specialty & $\begin{array}{l}\text { Mean } \\
\text { score }\end{array}$ & Subgroup & Specialty & $\begin{array}{l}\text { Mean } \\
\text { score }\end{array}$ & Subgroup \\
\hline 1 & Vascular surgery & 18.5 & $S$ & Gastroenterology & 65.0 & M & Neurology & 49.8 & M \\
\hline 2 & Gastroenterology & 17.0 & M & Vascular surgery & 58.8 & $S$ & Vascular surgery & 48.2 & M \\
\hline 3 & Orthopedics & 16.6 & $S$ & Transplantation & 58.5 & $S$ & Acute medicine & 48.1 & A \\
\hline 4 & Acute medicine & 15.6 & $M$ & Acute medicine & 58.1 & A & Respirology & 47.8 & $M$ \\
\hline 5 & Oncology & 13.6 & $M$ & Respirology & 56.5 & $M$ & Transplantation & 47.5 & $\mathrm{~S}$ \\
\hline 6 & Transplantation & 13.0 & $\mathrm{~S}$ & Neurology & 56.0 & $M$ & Gastroenterology & 47.3 & M \\
\hline 7 & General surgery & 12.8 & 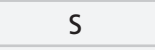 & Pathology & 55.9 & L & Nursing & 47.3 & $\mathrm{~N}$ \\
\hline 8 & Neurology & 11.8 & $M$ & Nephrology & 55.0 & $M$ & Cardiology & 47.0 & $M$ \\
\hline 9 & Anesthesiology & 11.5 & A & $\begin{array}{l}\text { Obstetrics and } \\
\text { gynecology }\end{array}$ & 54.0 & $S$ & General surgery & 46.1 & $S$ \\
\hline 10 & Pathology & 11.5 & L & Nursing & 53.5 & $\mathrm{~N}$ & Orthopedics & 45.7 & $S$ \\
\hline 11 & $\begin{array}{l}\text { Emergency } \\
\text { medicine }\end{array}$ & 11.4 & A & Cardiology & 53.3 & M & Pathology & 45.6 & L \\
\hline 12 & Nursing & 11.1 & $\mathrm{~N}$ & Critical care & 53.2 & A & Nephrology & 44.8 & $M$ \\
\hline 13 & Dermatology & 11.0 & M & Orthopedics & 53.1 & $S$ & $\begin{array}{l}\text { Emergency } \\
\text { medicine }\end{array}$ & 43.4 & A \\
\hline 14 & $\begin{array}{l}\text { Obstetrics and } \\
\text { gynecology }\end{array}$ & 10.4 & $\mathrm{~S}$ & $\begin{array}{l}\text { Emergency } \\
\text { medicine }\end{array}$ & 52.6 & A & $\begin{array}{l}\text { Obstetrics and } \\
\text { gynecology }\end{array}$ & 42.4 & $S$ \\
\hline 15 & Nephrology & 10.1 & M & General surgery & 52.1 & $\mathrm{~s}$ & Anesthesiology & 42.4 & A \\
\hline 16 & Radiology & 9.9 & L & Radiology & 51.9 & L & Critical care & 42.2 & A \\
\hline 17 & Respirology & 9.8 & M & Geriatrics & 50.6 & M & Radiology & 42.1 & L \\
\hline 18 & Pediatrics & 9.3 & $M$ & Anesthesiology & 50.1 & A & Oncology & 41.0 & M \\
\hline 19 & General practice & 9.1 & G & General practice & 49.1 & G & Dermatology & 41.0 & M \\
\hline 20 & Critical care & 9.0 & A & Oncology & 48.9 & $M$ & General practice & 40.3 & G \\
\hline 21 & Cardiology & 8.8 & $M$ & Dermatology & 47.5 & $M$ & Geriatrics & 40.2 & $M$ \\
\hline 22 & Geriatrics & 7.8 & $M$ & Pediatrics & 47.0 & $M$ & Pediatrics & 33.3 & $M$ \\
\hline
\end{tabular}


Interestingly, of the medical specialties listed in Table 3, neurologists were found to have the greatest psychopathic traits. Could it be that the phenomenon of cross contamination is at play and neurologists are in fact driving each other crazy?

\section{Limitations}

This study was undertaken in the United Kingdom, where the population is renowned worldwide to display the very British "stiff upper lip." Should this study have been undertaken using Canadians, who pride themselves on their humble nature, perhaps even the surgeons among them would have shamed the narcissistic British butchers with even lower scores; unless, of course, they were from Toronto.

The sampling in this study could have been improved by approaching equal numbers of health care professionals from individual specialties to take part in the study to reduce selection bias, which can skew results. Furthermore, sampling of the general population could have been expanded to target patients attending for treatment, which would have increased overall numbers in this cohort. This would have broadened general public participation and included members of the public who do not use social media, thus leading to more accurate general population norms.

Within this study, small numbers in health care subgroups may have led to some comparisons being underpowered. This is a limitation when interpreting the results.

Finally, it must be acknowledged that there is a clear conflict of interest. Two authors of this study are orthopedic residents who took it upon themselves to design and carry out research in psychology, a field not commonly associated with this particular brand of surgeon. If a pair of orthopods believe they can write a psychology paper, this only serves to emphasize that surgeons really are narcissistic by nature.

\section{Conclusion}

Our anesthesiologist colleague's comment that "all surgeons love themselves" is only partially true. Surgeons are significantly more narcissistic than many of their colleagues but less so than their patients. It remains to be seen whether theatre efficiency could be improved by the proposed removal of all reflective instrumentation. The suggestion that health care professionals are avaricious and untrustworthy can be refuted.

\section{References}

1. Bennett A. How much are junior doctors paid and why are they threatening to strike? The Telegraph 2015. Available: www. telegraph.co.uk/news/nhs/11887308/How-much-are-junior-doctors -paid-and-why-are-they-threatening-to-strike.html (accessed 2015 Aug. 24).
2. Wright O. Doctor, doctor: Why is my GP going on strike? Because a £53,000-a-year pension deal isn't enough. The Independent 2012. Available: www.independent.co.uk/life-style/ health-and-families/health-news/doctor-doctor-why-is-my-gp -going-on-strike-because-a-53000-a-year-pension-deal-isnt -enough-7805072.html (accessed 2015 Aug. 24).

3. Paulhus DL, Williams KM. The dark triad of personality: narcissism, Machiavellianism and psychopathy. J Res Pers 2002;36: 556-63.

4. Jones DN, Paulhus DL. Chapter 7. Machiavellianism. In: Leary MR, Hoyle RH, editors. Handbook of individual differences in social behaviour. London (UK): Guilford Press; 2009.

5. Machiavelli N. Il Principe. Florence (Italy): Antonio Blado; 1532.

6. Jakobwitz S, Egan V. The dark triad and normal personality traits. Pers Individ Dif 2006;40:331-9.

7. Lee K, Ashton MC. Psychopathy, Machiavellianism and narcissism in the five factor model and the HEXACO model of personality structure. Pers Individ Dif 2005;38:1571-82.

8. Raskin R, Terry H. A principle-components analysis of the narcissistic personality inventory and further evidence of its construct validity. J Pers Soc Psychol 1988;54:890-902.

9. Wai M, Tiliopoulos N. The affective and cognitive empathic nature of the dark triad of personality. Pers Individ Dif 2012;52:794-9.

10. Hare RD. Without conscience: the disturbing world of the psychopaths among us. New York: Guilford Press; 1999.

11. Del Gaizo AL, Falkenbach M. Primary and secondary psychopathic traits and their relationship to perception and experience of emotion. Pers Individ Dif 2008;45:206-12.

12. Christie R, Geis FL. Studies in Machiavellianism. New York: Academic Press; 1970.

13. Levenson MR, Kiehl JA, Fitzpatrick CM. Assessing psychopathic attributes in a noninstitutionalized population. J Pers Soc Psychol 1995;68:151-8.

14. Faul F, Erdfelder E, Lang AG, et al. G*Power 3: a flexible statistical power analysis program for the social, behavioral, and biomedical sciences. Behav Res Methods 2007;39:175-91.

15. Cohen J. Statistical power analysis for the behavioral sciences. 2nd ed. Mahwah (NJ): Lawrence Erlbaum Associates; 1988.

16. Subramanian P, Kantharuban S, Subramanian V, et al. Orthopaedic surgeons: As strong as an ox and almost twice as clever? Multicentre prospective comparative study. BMJ 2011;343:d7506.

17. Davidson J. Survey: surgeons are the most attractive doctor. Time 2013. Available: http://newsfeed.time.com/2013/08/30/ survey-surgeons-are-the-most-attractive-doctors (accessed 2015 Aug. 24).

Affiliations: Royal Infirmary of Edinburgh (Bucknall); School of Life, Sport and Social Sciences (Burwaiss, Charles), Edinburgh Napier University; University of Edinburgh Medical School (MacDonald, Clement), Edinburgh, United Kingdom

Contributors: Rhys Clement enjoyed the grandiosity of overseeing the study, contributing to data collection and revising the draft paper. While Rhys Clement was busy priding himself on his appearance, Vittoria Bucknall ruthlessly promoted herself to first author, drafting and revising the paper while contributing to data collection. Kathy Charles, displaying low levels of narcissistic and Machiavellian traits, was easily coerced into performing data analysis. Suendoss Burwaiss initiated the project and, with Deborah MacDonald, designed the data collection tools; they were excellent at data collection thanks to their high degree of emotional dissociation and ability to deal with rejection. All of the authors contributed to the critical revision of the manuscript, approved the final version to be published and agreed to act as guarantors of the work.

Acknowledgement: The authors thank Tom Carter for his astonishing good looks and for agreeing to pose for Figure 1. Unfortunately, we were unable to find a more representative anesthesiologist model on short notice.

Ethics approval: An ethics application was submitted using the Integrated Research Application System form to our local ethics committee, which deemed that ethical approval was not required for this study - a copy of the committee's response can be provided on request. Furthermore, our local National Health Service research and development department was contacted and gave permission to proceed with the study - this can also be provided on request. 